\title{
POST TRAUMATIC DISPLACEMENT OF TESTIS- A RARE CASE REPORT
}

Avadhut Dange, Satish Gireboinwad, Amit Aiwale, Ashok Shinde, Ishwar Kanbur.
1. Assistant Professor. Department of General Surgery, SRTRGMC, Ambajogai, Maharashtra.
2. Assistant Professor. Department of General Surgery, SRTRGMC, Ambajogai, Maharashtra.
3. Resident Senior. Department of General Surgery, SRTRGMC, Ambajogai, Maharashtra.
4. Resident Senior. Department of General Surgery, SRTRGMC, Ambajogai, Maharashtra.
5. Resident Senior. Department of General Surgery, SRTRGMC, Ambajogai, Maharashtra.

\section{CORRESPONDING AUTHOR: \\ Dr. Avadhut Narayan Dange, \\ 42, Model Colony, \\ Solapur. \\ E-mail: dravadhut@rediffmail.com}

\begin{abstract}
Traumatic displacement of the testis is a rare occurrence and is defined as the displacement of one or both testis to a position other than the scrotum (1).Traumatic displacement of testis is commonly a delayed diagnosis during treatment occurs as a consequence of high velocity road traffic accident( ${ }^{(2)}$ usually following a motorcycle collision, in what is referred to as "fuel tank injury". Early identification and subsequent surgical management is of utmost importance to maintain normal spermatogenesis in the displaced testis. We report a case of traumatic displacement of testis in superficial inguinal pouch in a young man presented 1 year after a road traffic accident. The clinical diagnosis was well supported by USG. The patient was successfully treated by inguinal exploration and repositioning of testis in scrotum, under spinal anesthesia.
\end{abstract}

KEY WORDS- Inguinal canal, testis

INTRODUCTION: Traumatic displacement of testis is a rare occurrence. Here we present a rare case of traumatic displacement of testis in SRTR Govt. hospital Ambajogai. Immediate diagnosis and treatment is recommended to prevent future complications like infertility and chronic discomfort. While dealing with traumatic injury of lower abdomen, the possibility of testicular displacement should be kept in mind and treated.

CASE REPORT: A 22yr male patient presented to OPD with complaint of displacement of testis in the inguinal region after accident since 1 year and discomfort in the displaced testis. On further enquiry patient gave history of motorbike handle injury following road traffic accident. He had a untidy wound in the inguinal region and noticed the displacement of the right testis. Patient went to doctor for the treatment of wound and also told about the displacement of the right testis. Doctor sutured the wound however patient was not further investigated.

On local examination, visible hypertrophic irregular scar of size $2 * 2 \mathrm{~cm}$ dimension in right mid inguinal region. Scrotum was well developed. Left testis was normally present in the scrotum while as right scrotum was empty.

Right testis was palpable at superficial inguinal pouch which was mobile (fig1), had a normal consistency and normal testicular sensation.

Ultrasound was done for confirmation of the right testis. The USG revealed, right testis in inguinal canal, of normal size and echo texture and without any focal lesion. The left testis was normal. The patient in this case had delayed presentation however testicular sensation were present suggesting viable testis. This was also confirmed by USG in the form of normal size 
and eco texture Hence patient was not further evaluated as management was going to unchanged.

The patient operated by right inguinal incision. On inguinal exploration, dense fibrosis was found in all layers of skin till superficial ring. The superficial inguinal ring was widened and whole medial cruise was easily visible but lateral cruse was involved in fibrosis. Testis and cord was pulled up in superficial inguinal pouch along with scrotal layers. The testis was present in superficial inguinal pouch (fig2) with cord structures looped on it (fig3). The testis was normal appearing on gross examination.

Reposition of the testis was done in the right scrotum. Narrowing of superficial inguinal ring done. Patient was stable in intraoperative and postoperative period.

DISCUSSION: Blunt scrotal trauma is not very uncommon occurrence in young adults but a testicular displacement is a rare complication of testicular trauma. It is defined as displacement of one or both normally located testes out of the scrotum. It was first described by Herbst and Polkey in 1936.(6) Testicular displacement commonly occurs following motorcycle collision due to the impact of the fuel tank on the perineum and the scrotum displacing the testis in a superior and lateral direction. These types of injuries are also referred to as "fuel tank injuries". (5). Patients usually present with empty scrotum and a painful palpable mass either in the inguinal region, prepubic area, or crural location.

Most common reported location for a dislocated testis is superficial inguinal pouch and occurs in approximately $40-50 \%$ of the cases. The next common areas in order of frequency of occurrence include pubic (18\%), canalicular (8\%), penile (8\%), intra-abdominal (6\%), perineal (4\%), and crural (2\%) approximately (3). Two types of testicular displacement have been described. (6)In Type 1testiculardisplacement, the testis is displaced to the inguinal canal or the abdominal cavity through the external /internal inguinal ring. In Type 2, the dislocated testis is located superficially in the subcutaneous regions such as the inguinal, pubic, crural, penile, or acetabular regions. This case is of type II testicular displacement. A "Compound displacement" of the testis is extremely rare event and in this category traumatic extrusion of the testis occurs through the skin of the scrotum.

The contributory factors may include cremastric muscle reflex, widely open superficial inguinal ring, an indirect inguinal hernia or an atrophic testis(7).It may be associated with torsion of spermatic cord and other severe injuries like pelvic bone fracture. In most of the cases the displacement occurs immediately after trauma but may develop days or even weeks later. In most of the cases the displacement is unilateral but case with bilateral displacement has been reported.

The diagnosis is usually based on thorough physical examination showing empty hemiscrotum and a palpable tender mass. Ultra sonography may be useful in doubtful cases. Doppler ultra sonography helps to evaluate the viability of and the blood flow to the testis. Other investigations like Computed Tomography may be useful in extreme cases to know exact location of testis.

The emergency treatment includes closed reduction if patient presents early and testis is palpable in upper scrotum. If this strategy proves successful, follow up by USG and Doppler for testicular ischemia, is recommended. In case of delay or recurrence, formal exploration with open reduction andorchiopexy is advised. In the displacement of testis the displaced testis belongs to native scrotum with a normal cord length. Hence chances of going back of the testis in the new position is rare unless is forcefully pushed. This can happen in any testis either 
orchiopexied or non orchiepexied testis. Secondly chances of injury to the orchiopexied testis is more because it could not be displaced hence we only repositioned the testis to its normal position.

Complications depends on the compromise of blood supply of the testis and its duration of stay outside the scrotum which include torsion, testicular ischemia, diffuse atrophy of seminiferous tubules( ${ }^{(8)}$, severe impairment of spermatogenesis(9), and acute and chronic discomfort interfering with daily activities.

Traumatic displacement of testis is a rare occurrence. Immediate diagnosis and treatment is recommended to prevent future complications like infertility and chronic discomfort. While dealing with traumatic injury of lower abdomen, the possibility of testicular displacement should be kept in mind and treated.

\section{REFERENCES:}

1. Ockuly EA. Traumatic luxation of the testis. Am J Surg 1946; 71:93-95.

2. Shefi S, Mor Y, Dotan ZA, et al. Traumatic testicular displacement: A case report and review of published reports. Urology 1999;54:744.

3. Schwartz SL, Faerber GJ.Displacement of the testis as a delayed presentation of scrotal trauma. Urology 1994;43(5):743-745.

4. Claubry E: Observation sur une retrocession subite des deux testicules dans l'abdomen, a la suite dune violente compressionde la partie inferieure de la paroi abdominale par une roue de charrette. J Gen Med Chir Pharmacol 64: 325.1818.

5. Kilian CA, Paz DA, Patel SA, Austin MJ, Richman KM, Pretorius DH. False diagnosis of ruptured testes in a case of traumatic displacement. JUM 2009;28:549-53.

6. Ihama Y, Fuke C, Miyazaki T. A two- rider motorcycle accident involving injuries around groin area in both the driver and the passenger. Legal Med 2007;9:274-7.

7. Aslam MZ, Thwaini A, Sundaram SK. Testicular displacement: a rare consequence of blunt scrotal injury. Can Urol Assoc J 2009;3(3):E1-E3.

8. Madden JF. Closed reduction of a traumatically dislocated testicle. Acad Emerg Med 1994;1:272-5.

9. Hayami S, Ishigooka M, Suzuki Y, et al. Pathological changes of traumatic dislocated testis. Urol Int 1996;56:129-132.

Figure1-Testies in right inguinal region

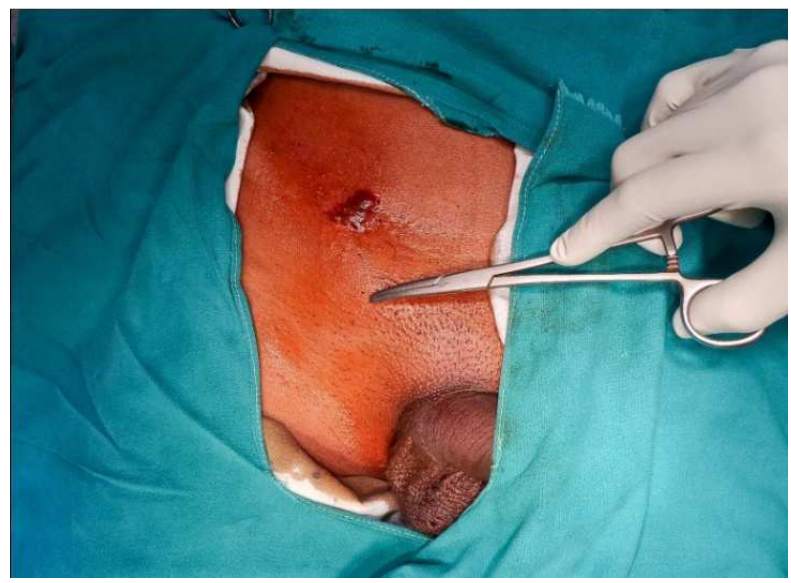


Figure 2- Right displaced testis with cord structures

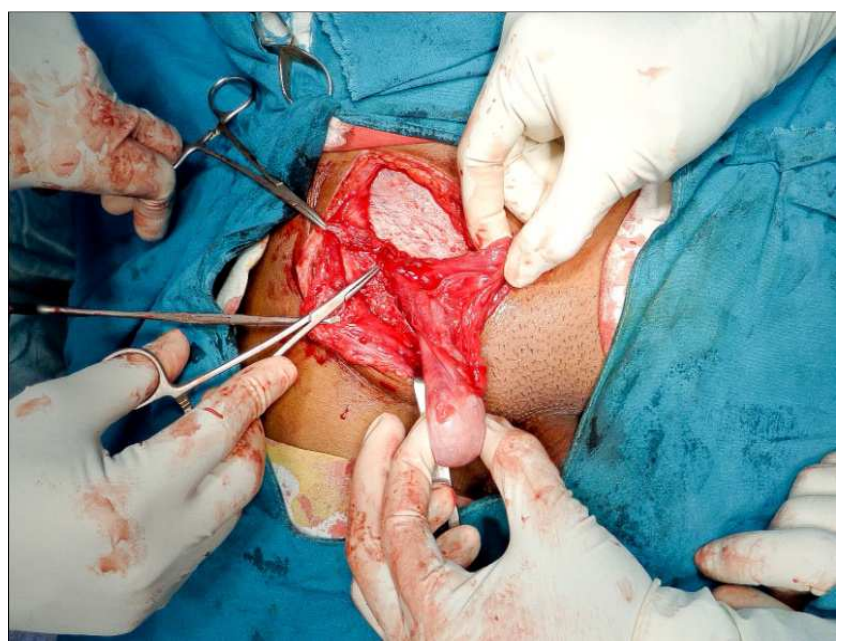

Figure 3 - Cord structures mobilized

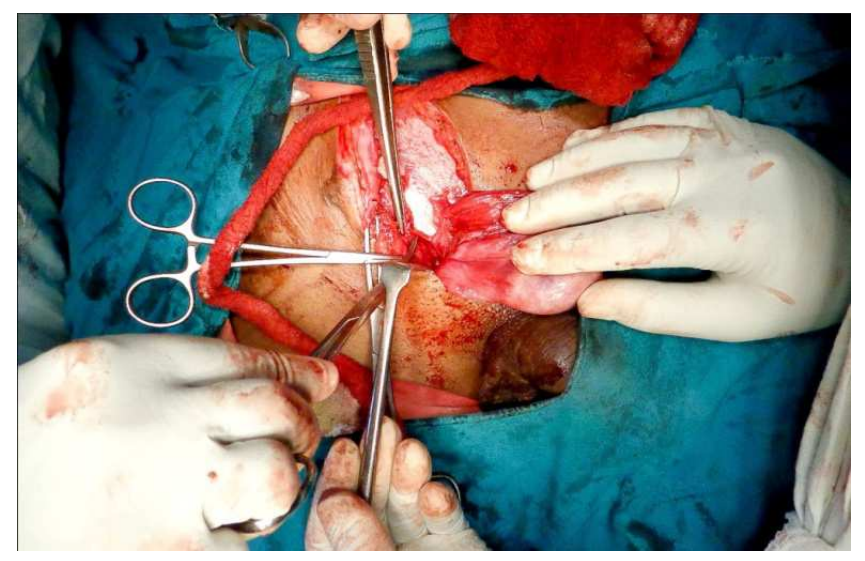

Figure 4- Reposition of testis in scrotal sac indicated by arrow with narrowing of superficial inguinal ring done.

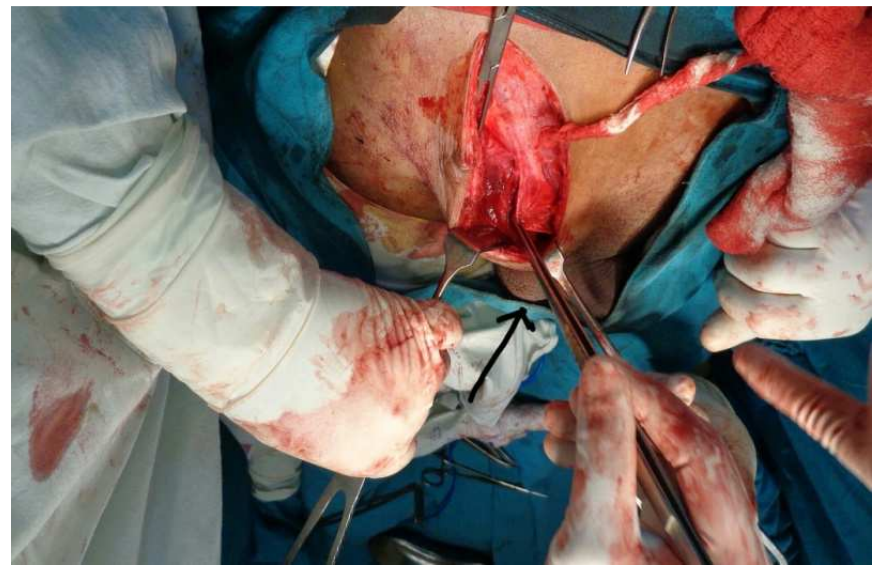

